\title{
Effect of the interaction between food state and the action of estrogen on oxytocinergic system activity
}

\author{
F Lucio-Oliveira and C R Franci \\ Department of Physiology, School of Medicine of Ribeirão Preto, University of São Paulo, Avenida Bandeirantes, 3900, 14049-900 Ribeirão Preto - SP, Brazil \\ (Correspondence should be addressed to C R Franci; Email: crfranci@fmrp.usp.br)
}

\begin{abstract}
Increased plasma osmolality by food intake evokes augmentation of plasma oxytocin (OT). Ovarian steroids may also influence the balance of body fluids by acting on OT neurones. Our aim was to determine if estrogen influences the activity of OT neurones in paraventricular nucleus (PVN) and supraoptic nucleus (SON) under different osmotic situations. Ovariectomized rats (OVX) were treated with either estradiol $\left(\mathrm{E}_{2}\right)$ or vehicle and were divided into three groups: group I was fed ad libitum, group II underwent $48 \mathrm{~h}$ of fasting, and group III was refed after $48 \mathrm{~h}$ of fasting. On the day of the experiment, blood samples were collected to determine the plasma osmolality and OT. The animals were subsequently perfused, and OT/FOS immunofluorescence analysis was conducted on neurones in the PVN and the

SON. When compared to animals which were fasted or fed ad libitum, the plasma osmolality of refed animals was higher, regardless of whether they were treated with vehicle or $\mathrm{E}_{2}$. We observed neural activation of OT cells in vehicle- or $\mathrm{E}_{2}$-treated OVX rats refed after $48 \mathrm{~h}$ of fasting, but not in animals fed ad libitum or in animals that only underwent $48 \mathrm{~h}$ of fasting. Finally, the percentage of neurones that co-expressed OT and FOS was lower in both the PVN and the SON of animals treated with $\mathrm{E}_{2}$ and refed, when compared to vehicle-treated animals. These results suggest that $E_{2}$ may have an inhibitory effect on OT neurones and may modulate the secretion of OT in response to the increase of osmolality induced by refeeding.

Journal of Endocrinology (2012) 212, 129-138
\end{abstract}

\section{Introduction}

Hydroelectrolytic homeostasis is maintained by several endocrine and behavioral responses that control sodium appetite, water ingestion, and the secretion of oxytocin (OT) and vasopressin (AVP) from the neurohypophysis (Fitzsimons 1998, McKinley \& Johnson 2004). An increase in plasma osmolality causes a rise in plasma OT levels that, in turn, induces the excretion of sodium and chloride (Balment et al. 1980, Caligioni \& Franci 2002).

$\mathrm{OT}$ is well known for its role in female reproduction where it stimulates uterine contractions and initiates milk ejection during lactation (Van Tol et al. 1988, Crowley et al. 1993). It also appears to participate in some functions that are essential for the success of reproduction, such as penile erection (Argiolas 1992), female sexual behavior (Caldwell 1992), maternal behavior (Kendrick et al. 1997) and stimulation of GnRH preovulatory secretion (Selvage \& Johnston 2001). This hormone is synthesized by magnocellular neurosecretory cells in the supraoptic nucleus (SON) and paraventricular (PVN) nucleus of the hypothalamus. These regions are intrinsically sensitive to changes in osmolality and are activated by hypertonicity (Bourque 1989, McKinley et al. 1994, Oldfield et al. 1994). In addition to the direct or indirect natriuretic action of OT, there is evidence that central OT also acts to modulate sodium appetite (Stricker \& Verbalis 1987). The central administration of OT induces the expression of the FOS protein in regions involved in the control of food intake (Olson et al. 1993). Plasma osmolality also increases in response to food intake and the ingestion of sodium (Bloom et al. 1975, Houpt et al. 1983, Burlet et al. 1992); this increase involves both inhibitory and excitatory control mechanisms (Cunningham \& Sawchenko 1991).

Although the initial focus of OT research was on its role in reproduction, its role in hydroelectrolytic control is also under investigation now (Jones \& Pickering 1969, Balment et al. 1980, Caligioni \& Franci 2002). There are several pieces of evidence indicating that gonadal steroids regulate the function of OT neurones. Some studies have shown a variation both in the levels of OT in the PVN, the SON and the neurohypophysis and in the plasma concentration of OT during the estrous cycle, with higher oxytocinergic activity during pro-estrous (Crowley et al. 1978, Sarkar \& Gibbs 1984, Greer et al. 1986, Windle \& Forsling 1993). The expression of OT mRNA in the magnocellular neurones of the PVN (Van Tol et al. 1988) increases at the onset of puberty and decreases after castration (Miller et al. 1989), suggesting a possible influence of estrogen on OT expression levels. 
The administration of estrogen stimulates the peripheral release of OT, increases the electrical activity in OT neurones and alters the structural organization of both the cell bodies and the dendrites of oxytocinergic neurones (Negoro et al. 1973, Amico et al. 1981, Caldwell et al. 1988). Taken together, these studies indicate that the action of estrogen on magnocellular neurones contributes to the regulation of OT release (Jirikowski et al. 1988, Van Tol et al. 1988, Miller et al. 1989, Amico et al. 1995, Salonia et al. 2005, Somponpun 2007). In contrast, some studies have found that estrogen has no significant effect on OT expression in the PVN (Van Tol et al. 1988, Crowley et al. 1993), while yet another group has shown that treatment with estrogen decreases the expression of OT mRNA in the PVN of ovariectomized rats (OVX; Shughrue et al. 2002). Thus, the exact relationship between estrogen and the oxytocinergic system remains under debate and the reason for these discrepancies is unclear. One possibility is that the oxytocinergic system responds differently depending on the concentration of estrogen present.

Despite mounting evidence that estrogen acts on OT neurones, it is still unclear exactly how this regulation occurs, although it may involve both direct and indirect effects. Several studies have shown that ER- $\beta$ and its mRNA are both present in OT and AVP neurones. However, ER- $\beta$ expression is higher in AVP neurones (Shughrue et al. 1996, Simonian \& Herbison 1997, Hrabovszky et al. 1998, 2004, Somponpun \& Sladek 2003, Suzuki \& Handa 2005, Somponpun 2007). There is strong expression of ER- $\beta$ in areas that lack or have low levels of ER- $\alpha$, including both parvocellular and magnocellular neurones (Shughrue et al. 2002) in the SON and the PVN (Shughrue et al. 1996, Osterlund et al. 2000, Shughrue \& Merchenthaler 2001, Sladek \& Somponpun 2007). Some researchers have shown that AVP neurones, but not OT neurones, respond to refeeding (Timofeeva et al. 2005), but they used males. Therefore, they did not analyze the correlation of estrogen with oxytocinergic system in response to the increase of osmolality induced by refeeding.

In this study, we aimed to determine if the food state associated with estrogen activity alters the activity of the oxytocinergic system in the PVN and the SON.

\section{Materials and Methods}

\section{Animals}

Adult female Wistar rats weighing 160-180 g were housed in individual cages under controlled conditions of temperature $\left(22 \pm 1^{\circ} \mathrm{C}\right)$ and light (12 h light:12 h darkness cycle) and were allowed free access to food and water. Bilateral OVX was performed under $2 \cdot 5 \%$ tribromoethanol $(1 \mathrm{ml} / 100 \mathrm{~g}$ of body weight, i.p.). All animal experimental protocols and manipulations were approved by the ethics committee of the Medical School of Ribeirão Preto, University of São Paulo.

\section{Experimental protocol}

Fourteen days after surgery (OVX), the animals weighing 250-280 g were divided into three groups. Animals in group I were fed standard food ad libitum, those in group II were fasted for $48 \mathrm{~h}$ with access to water, and the rats in group III were refed during $2 \mathrm{~h}$ with standard food after $48 \mathrm{~h}$ of fasting. During the 3 days before the experiment began, the animals were treated with estradiol $\left(E_{2}\right)$ cypionate $(10 \mu \mathrm{g} / 0 \cdot 1 \mathrm{ml}$ per animal) or vehicle (oil). On the 4th day (at $1500 \mathrm{~h}$ ), after an ad libitum meal (group I), $48 \mathrm{~h}$ of fasting (group II) or refeeding (group III), the animals were anesthetized with $2 \cdot 5 \%$ tribromoethanol $(1 \mathrm{ml} / 100 \mathrm{~g}$ of body weight, i.p.) so that blood could be withdrawn from the heart ventricle. Then, the rats were transcardially perfused through the ascending aorta with $\sim 80 \mathrm{ml}$ of $0 \cdot 01 \mathrm{M}$ PBS (pH 7.4) followed by $320 \mathrm{ml}$ cold $4 \%$ paraformaldehyde (PFA).

\section{Osmolality}

Plasma osmolality was measured by a Fiske Mark osmometer (Fiske Associates, Norwood, MA, USA) using freezing point depression.

\section{Hormone measurement}

Plasma OT levels were measured by RIA. All samples from the same experiment were measured in the same assay to avoid interassay variation. The minimum detectable concentration was $0.8 \mathrm{pg} / \mathrm{ml}$. The RIA was performed, as previously described (Morris \& Alexander 1989), using a specific antiserum, which was a generous gift from Dr Mariana Morris from Wright State University (OH, USA), a standard from Bachem-Peninsula Labs (San Carlos, CA, USA) and a secondary antibody produced by Dr Franci's Laboratory (School of Medicine of Ribeirão Preto, University of São Paulo, Brazil). The results were reported as means \pm s.E.M.

\section{Immunofluorescence}

Tissue preparation Rat brains were removed immediately after perfusion and post-fixed in 4\% PFA for $2 \mathrm{~h}$. Later, the brains were immersed in 30\% sucrose in PBS until the tissue was saturated, frozen in cooled isopentane and stored at $-70{ }^{\circ} \mathrm{C}$ until sectioning. Serial coronal sections $(14 \mu \mathrm{m})$ throughout the PVN and the SON were obtained using a cryostat and mounted onto slides.

Double-label immunofluorescence Sections of the PVN and the SON were rinsed in PBS multiple times, followed by a rinse in $0.1 \mathrm{M}$ glycine in PBS to remove any excess aldehydes. After the washes in PBS, the sections were blocked in PBS containing $0 \cdot 1 \%$ Triton X-100 and 1\% BSA and were incubated with primary antibodies. Sections were stained for OT/FOS with an overnight incubation at room temperature with mouse monoclonal anti-OT antiserum 
diluted 1:2000 (a kind gift from Dr Harold Gainer, National Institute of Health, Bethesda, MD, USA) and rabbit polyclonal anti-FOS (SC-52, Santa Cruz Biotechnology, Santa Cruz, CA, USA) diluted 1:500 in PBS containing 0.1\% Triton X-100 and 1\% BSA. After the overnight incubation, the sections were rinsed and incubated for $1 \mathrm{~h}$ in the appropriate secondary antibodies. To visualize OT, we used a goat anti-mouse IgG labeled with Alexa Fluor 488; and to visualize FOS, we used a goat anti-rabbit IgG labeled with Alexa Fluor 594 (Molecular Probes, Grand Islands, NY, USA). Next, the slides were rinsed in PBS and coverslipped with Fluoromount-G (Electron Microscopy Sciences, Hatfield, PA, USA). Tissue sections with immunoreactive neurones expressing OT and/or FOS were examined using an Axioskope 2 Plus microscope, and the images were captured with a Zeiss AxioCam digital camera (Carl Zeiss, Hallbergmoos, Germany). Subdivisions of the PVN and the SON were identified according to the Swanson brain atlas (Swanson 1992). Anterior (PaMA) and medial (PaMM) magnocellular subdivisions of the PVN were defined as -0.83 and $-1.53 \mathrm{~mm}$, respectively, from bregma and the SON was located at $-0.83 \mathrm{~mm}$ from bregma. The immunoreactive neurones were quantified with the aid of Image J software (National Institutes of Health). In each photomicrograph, the number of neurones that expressed FOS, OT and OT/FOS in the PVN and the SON was counted. Next, we calculated the mean number of labeled neurones in two to three brain sections from similar anatomic levels of PVN and SON for each animal.

Immunocytochemical controls The omission of either the primary or the secondary antibody in single-label experiments resulted in no labeling (data not shown). For each double-label combination, primary antibodies were titrated to establish the maximum dilutions that provided robust signals with minimum nonspecific staining.

\section{Statistical analysis}

Data were analyzed by two-way ANOVA followed by a Bonferroni post-hoc test. The data were presented as means \pm S.E.M. Differences were considered significant when $P<0 \cdot 05$.

\section{Results}

\section{Osmolality}

Figure 1A shows that the plasma osmolality $\left(\mathrm{mOsm} / \mathrm{kg} \mathrm{H}{ }_{2} \mathrm{O}\right)$ of OVX animals treated with the vehicle was significantly higher in the group that was refed with standard food after $48 \mathrm{~h}$ of fasting $(318 \cdot 1 \pm 1 \cdot 4)$ than in rats fed ad libitum $(305.4 \pm 1 \cdot 6, P<0.001)$ or in rats that were fasted for $48 \mathrm{~h}$ $(301 \cdot 6 \pm 1 \cdot 4, P<0 \cdot 001)$. Similarly, the plasma osmolality of OVX animals treated with estrogen was significantly higher
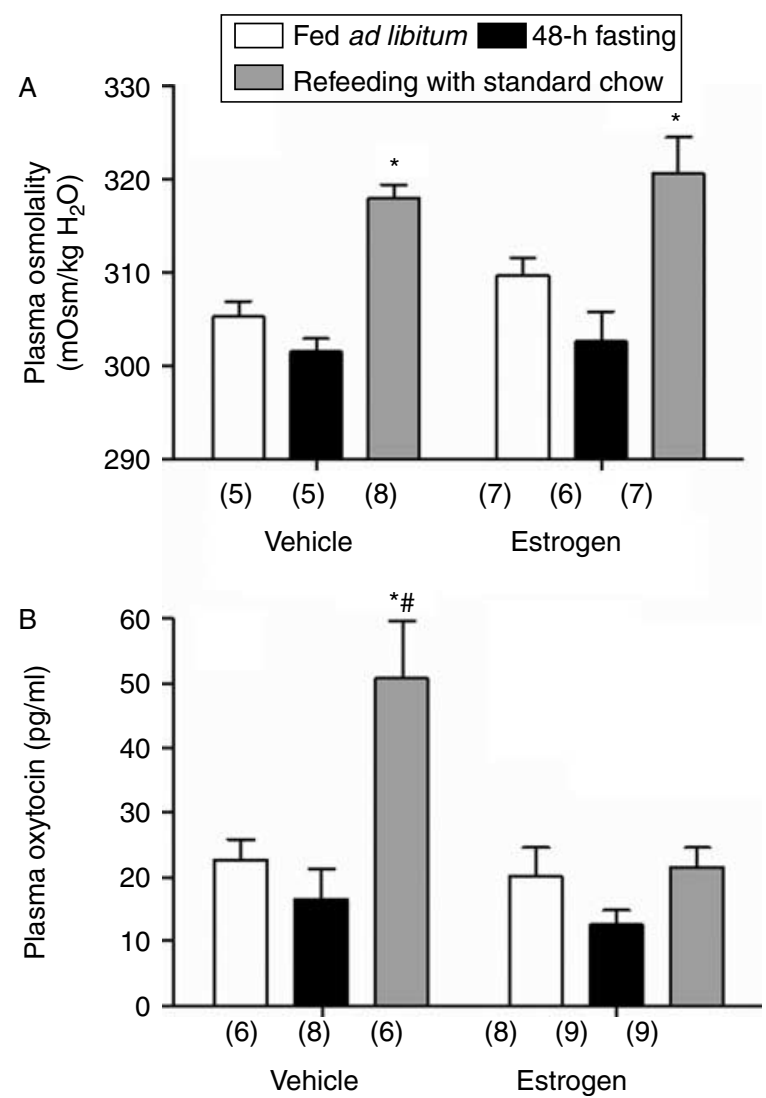

Figure 1 (A) Plasma osmolality, expressed in $m O s m / k g ~ \mathrm{H}_{2} \mathrm{O}$, in each experimental group. (B) Plasma OT concentration of ovariectomized $(O V X)$ rats treated with vehicle or estrogen. Differences: ${ }^{*} P<0 \cdot 05$ compared to groups fed ad libitum and those that were fasted for $48 \mathrm{~h}$ when given the same treatment and $\# P<0.05$ compared to animals refed with standard food and treated with estrogen as opposed to vehicle. Results are expressed as the mean \pm S.E.M. Number between parentheses indicates the group size.

in the group refed with standard food after $48 \mathrm{~h}$ of fasting $(320 \pm 3 \cdot 8)$ compared to the rats that were fed ad libitum $(309 \cdot 7 \pm 1 \cdot 9, P<0 \cdot 001)$ and animals that were fasted for $48 \mathrm{~h}$ $(302 \pm 3 \cdot 2, P<0 \cdot 05)$. However, there was no significant difference between the treatments (vehicle or estrogen) in any of the three groups.

\section{Hormone measurement}

Figure 1B shows plasma OT $(\mathrm{pg} / \mathrm{ml})$ levels in OVX animals treated with either vehicle or estrogen. The plasma OT levels of the group that was fasted for $48 \mathrm{~h}(16 \cdot 5 \pm 5)$ were similar to the levels of the group fed ad libitum $(22 \cdot 7 \pm 3)$, when both were treated with the vehicle. However, these levels increased in the group that was refed with standard food after $48 \mathrm{~h}$ of fasting $(50 \cdot 7 \pm 9)$ when compared either to the group that was fasted for $48 \mathrm{~h}(16 \cdot 5 \pm 5, P<0 \cdot 001)$ or to the group that was fed ad libitum $(22 \cdot 7 \pm 3, P<0 \cdot 002)$. In OVX animals treated with estrogen, no significant differences were observed 
among any of the groups. Therefore, estrogen treatment seems to have hindered the increase in plasma OT levels that was induced by the osmotic stimulus caused by refeeding after $48 \mathrm{~h}$ of fasting. This finding was confirmed by the observation that plasma OT levels were significantly higher in the vehicletreated group $(50 \cdot 7 \pm 9)$ than in the estrogen-treated group $(21 \cdot 6 \pm 2, P<0 \cdot 001)$.

\section{Immunofluorescence}

The data show (Fig. 2A) that there was no significant difference in the number of OT neurones in the PaMA between vehicle- or estrogen-treated OVX animals among any of the three food states (fed ad libitum, $48 \mathrm{~h}$ of fasting, or refed with standard food after $48 \mathrm{~h}$ of fasting). The same result was found for OT neurones in the PaMM (Fig. 2B) with the exception of animals that underwent $48 \mathrm{~h}$ of fasting. In this study, the number of OT neurones was lower in animals treated with estrogen $(60 \pm 6 \cdot 6, P<0 \cdot 03)$, as opposed to vehicle $(80 \pm 9 \cdot 1)$. In the SON (Fig. $2 \mathrm{C}$ ), there were no differences among any of the groups in the number of OT neurones between vehicle- or estrogen-treated animals. However, for the three groups of vehicle-treated animals, the number of OT neurones was significantly lower in those fed ad libitum $(43 \pm 1 \cdot 7, P<0 \cdot 05)$ compared to those that were refed after $48 \mathrm{~h}$ of fasting $(70 \pm 5 \cdot 4)$.

As shown in Fig. 3A, in OVX rats treated with vehicle, the number of FOS-immunoreactivity (-ir) neurones in the PaMA was significantly higher in animals refed after fasting $(28 \cdot 8 \pm 2 \cdot 1, P<0 \cdot 001)$ than in those fed either ad libitum $(0 \cdot 3$ $\pm 0 \cdot 2)$ or after $48 \mathrm{~h}$ of fasting $(0 \cdot 4 \pm 0 \cdot 4)$. The number of FOS-ir neurones in the PaMA was also significantly higher in refed vehicle-treated animals $(28 \cdot 8 \pm 2 \cdot 1, P<0 \cdot 001)$ than in refed animals treated with estrogen $(10 \cdot 6 \pm 3 \cdot 7)$. In the animals treated with estrogen, the number of FOS-ir neurones in the PaMA was significantly higher in the group refed after fasting $(10 \cdot 6 \pm 3 \cdot 7, P<0 \cdot 01)$ than in the group fed ad libitum $(0 \pm 0 \cdot 3)$.

The number of FOS-ir neurones in the PaMM (Fig. 3B) was not significantly different among any of the animals treated with estrogen and subjected to the three different food states. However, in vehicle-treated animals, the number was significantly higher in the group refed after fasting $(53.6 \pm 1 \cdot 1, P<0 \cdot 001)$ when compared to the group fed ad libitum $(0.5 \pm 0.5)$ and that underwent a 48 -h fasting period $(0 \cdot 8 \pm 0 \cdot 5)$. The number of FOS-ir neurones in the PaMM from the vehicle-treated group that was refed after fasting was also higher $(53 \cdot 6 \pm 1 \cdot 1, P<0 \cdot 001)$ than the animals treated with estrogen and refed after fasting $(12 \pm 6 \cdot 3)$.

In the SON of animals refed after fasting for $48 \mathrm{~h}$ (Fig. 3C), the number of FOS-ir neurones was significantly higher in vehicle-treated animals $(80 \cdot 8 \pm 8 \cdot 6, P<0 \cdot 001)$ than in animals treated with estrogen $(47 \cdot 3 \pm 6 \cdot 6)$. However, both groups showed a higher number of FOS-ir neurones when compared to the animals fed ad libitum $(0 \cdot 1 \pm 0 \cdot 1 ; 0 \pm 0)$ and animals that underwent $48 \mathrm{~h}$ of fasting $(0 \pm 0 ; 4 \cdot 4 \pm 1 \cdot 2)$ for both treatments.
We also looked for FOS-ir co-expression in OT neurones from the PVN and the SON (Figs 4 and 5). Little or no co-expression was observed in the PVN (both PaMA and PaMM) and the SON from animals that were fed ad libitum or fasted for $48 \mathrm{~h}$ and were treated with either estrogen or vehicle. However, co-expression was found in these areas in

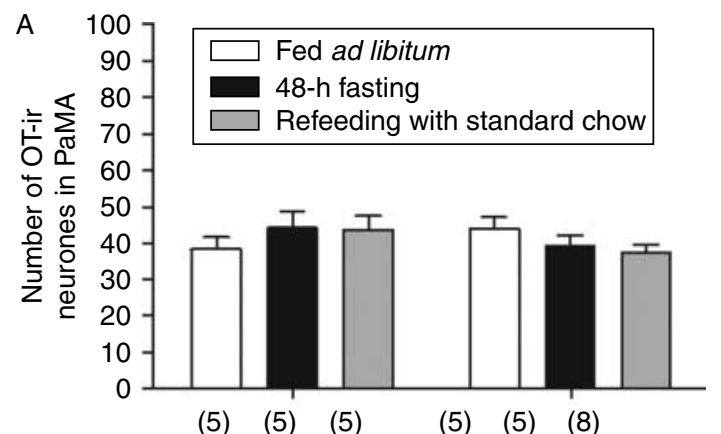

Vehicle Estrogen
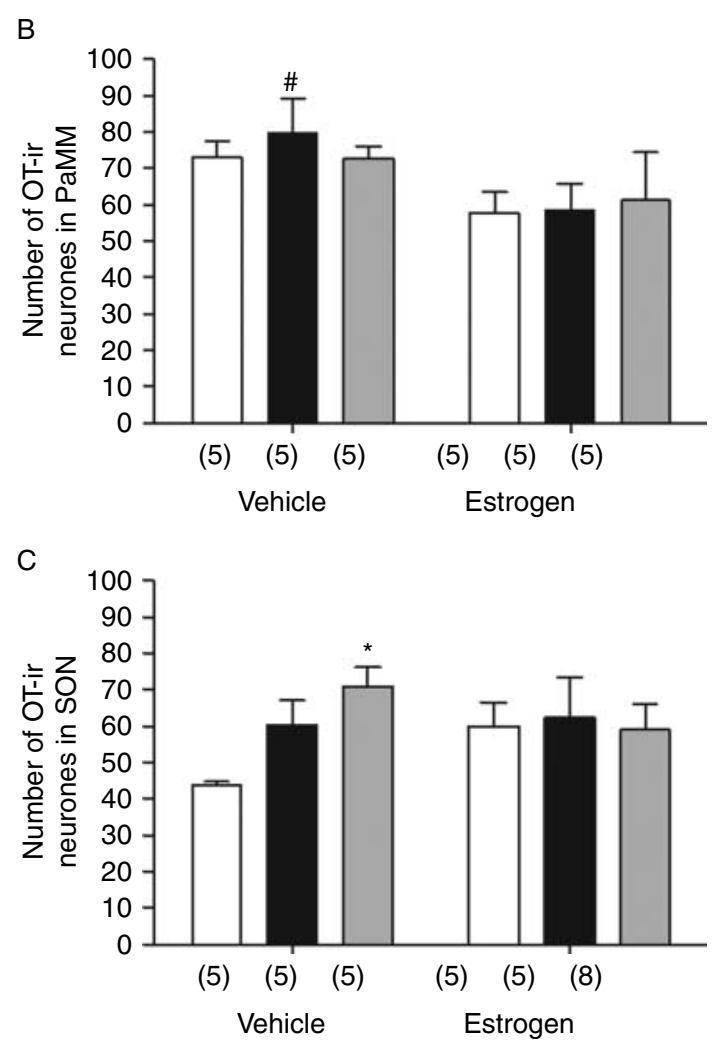

Figure 2 The number of OT-ir neurones in (A) the anterior magnocellular part (PaMA), (B) the medial magnocellular part $(\mathrm{PaMM})$ of paraventricular nucleus and $(\mathrm{C})$ the supraoptic nucleus $(\mathrm{SON})$ of vehicle- or estrogen-treated ovariectomized (OVX) rats. Differences: $\# P<0 \cdot 05$ compared to estrogen-treated animals that underwent $48 \mathrm{~h}$ of fasting and $* P<0.05$ compared to animals fed ad libitum and given the same treatment. Results are expressed as the mean \pm S.E.M. Number between parentheses indicates the group size. 

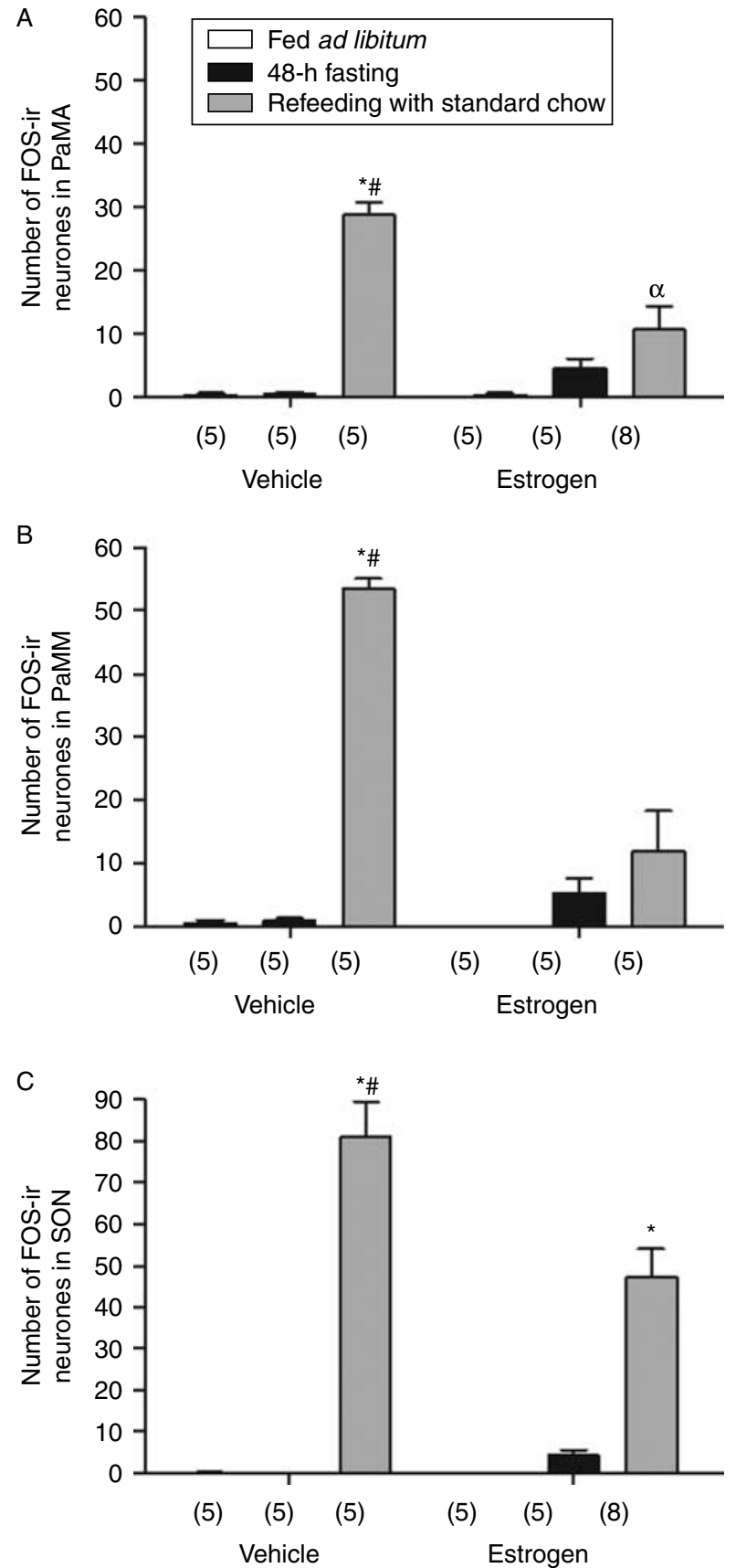

Figure 3 The number of FOS-ir neurones in (A) the anterior magnocellular part (PaMA), (B) the medial magnocellular part (PaMM) of the paraventricular nucleus and (C) the supraoptic nucleus (SON) of vehicle- or estrogen-treated OVX rats.

Differences: $* P<0 \cdot 05$ compared to animals fed ad libitum and those that were fasted for $48 \mathrm{~h}$ when given the same treatment; $\# P<0.05$ compared to animals refed with standard food and treated with estrogen; $\alpha$ represents statistical significance compared to animals fed ad libitum and treated with estrogen. Results are expressed as the mean \pm s.E.M. Number between parentheses indicates the group size. animals refed after fasting and treated with vehicle (PaMA $=$ $42 \cdot 9 \pm 6 \cdot 1 ; \mathrm{PaMM}=48 \pm 5 \cdot 2 ; \mathrm{SON}=52 \cdot 5 \pm 7 \cdot 8$ FOS-OT neurones/section) or with estrogen (PaMA $=11 \cdot 9 \pm 5 \cdot 3$; $\mathrm{PaMM}=2 \cdot 9 \pm 1 \cdot 8 ; \mathrm{SON}=24 \cdot 5 \pm 6 \cdot 2$ FOS-OT neurones/ section). Statistically significant differences were demonstrated when these values were compared to the groups fed ad libitum $(P<0 \cdot 001)$ and those that were fasted for $48 \mathrm{~h}$ $(P<0 \cdot 01)$. Moreover, the FOS/OT co-expression in the PaMA, the PaMM and the SON from animals refed after fasting was significantly higher in animals treated with vehicle than in animals treated with estrogen.

\section{Discussion}

It is well established in the literature that OT magnocellular neurones from the PVN and the SON project to the neurohypophysis. From there, the hormone OT is released to affect reproductive function (Russell \& Leng 1998, Fisher et al. 2006) and maintain hydroelectrolytic homeostasis, which is regulated by changes in plasma osmolality (Balment et al. 1980, McKinley \& Johnson 2004). We found a significant increase in plasma osmolality in $E_{2}$-primed and unprimed OVX animals that were refed with standard food after fasting when compared to animals fed ad libitum or animals that were fasted for $48 \mathrm{~h}$. Our results are in keeping with the results of a previous study which showed that refeeding may increase plasma osmolality (Gill et al. 1985, Burlet et al. 1992). The estrogen treatment did not change this response. Previous reports had also shown a similar response of estrogen (Caligioni \& Franci 2002, Hartley et al. 2004).

Plasma OT levels in all groups were higher than previously reported values because we did collect the blood under anesthesia. However, we did not observe a significant difference in plasma OT levels in $\mathrm{E}_{2}$-primed and unprimed OVX animals after $48 \mathrm{~h}$ of fasting when compared to animals fed ad libitum, regardless of estrogen treatment. In this study, we also analyzed photomicrographs from portions of the anterior and medial magnocellular PVN and the SON of OVX animals that were fasted for $48 \mathrm{~h}$. There was no expression of FOS in magnocellular OT neurones of these nuclei in vehicle- or estrogen-treated animals. Previous studies showed no change in OT levels in the PVN and the SON from rats that were fasted for $48 \mathrm{~h}$ (Burlet et al. 1992). Thus, it appears that the OT magnocellular neurones in these nuclei do not participate in the responses to $48 \mathrm{~h}$ of fasting.

In contrast, our results have shown that refeeding after $48 \mathrm{~h}$ of fasting induced OT secretion and FOS expression in the PVN (anterior and medial magnocellular portion) and the SON of unprimed OVX animals to a greater extent than in $\mathrm{E}_{2}$-primed OVX animals. Moreover, approximately half of the neurones that expressed FOS protein in the PVN and the SON were OT-ir. FOS expression has been reliably used to assess brain activity in response to food intake (Naimi et al. 1997, Timofeeva et al. 2002). It is also known that OT and AVP neurones in the PVN and the SON express FOS in 
response to an increase in osmolality (Somponpun \& Sladek 2003, Ruginsk et al. 2007, Vilhena-Franco et al. 2011).

Timofeeva et al. (2005) have shown that AVP neurones, but not OT neurones, respond to refeeding. The difference

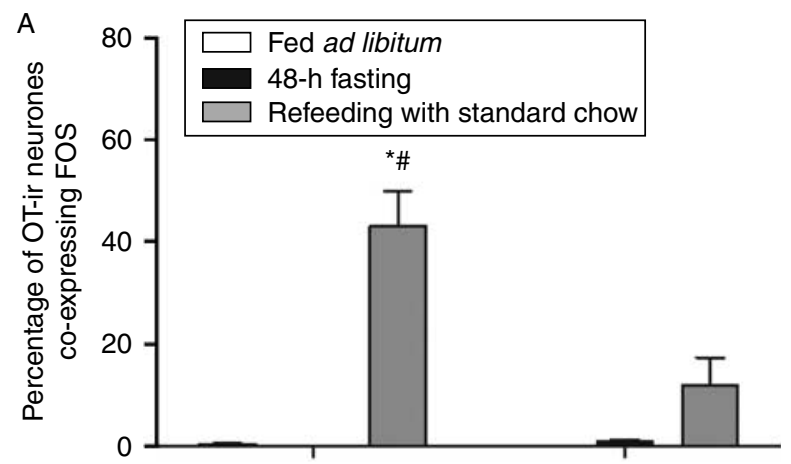

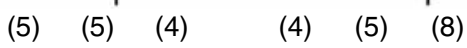

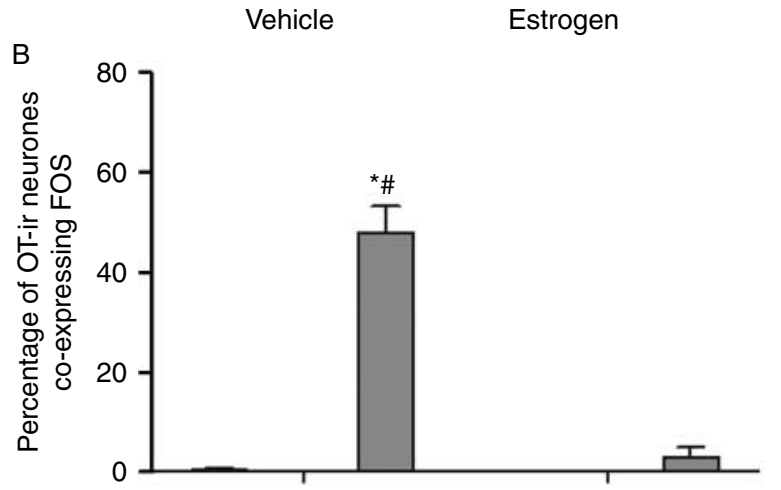

(5) (5)

(5)

(4) (4)

(5)

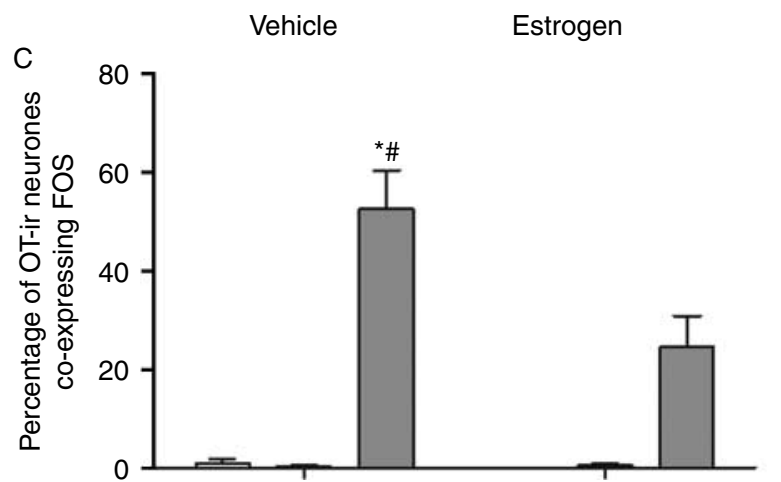

(5) (5) (5)

(4) (5)

(8)

Vehicle

Estrogen

Figure 4 The percentage of OT-ir neurones that co-expressed FOS-ir in the $(\mathrm{A})$ anterior magnocellular part (PaMA), (B) medial magnocellular part (PaMM) of the paraventricular nucleus and (C) supraoptic nucleus (SON) of vehicle- or estrogen-treated OVX rats. Differences: ${ }^{*} P<0 \cdot 05$ compared to animals fed ad libitum and those that were fasted for $48 \mathrm{~h}$ when given the same treatment and $\# P<0.05$ compared to animals refed with standard food and treated with estrogen. Results are expressed as the mean \pm S.E.M. Number between parentheses indicates the group size. between this report and our results may be due to the sexual difference, as they used males. Björkstrand \& Uvnãs-Moberg (1996) studied the effect of OT injection on food intake and daily weight gain in males and females from two substrains of Sprague-Dawley rats. They demonstrated that central, but not peripheral OT injection, caused lower food intake and daily weight gain in females than in males.

The potential involvement of circumventricular organs, such as the subfornical organ (SFO), in monitoring plasma osmolality after hyperosmotic challenge or after feeding has been suggested previously (Starbuck \& Fitts 2002, Hiyama et al. 2004). The hypertonicity of the extracellular fluid activates the SFO and the AV3V regions, which in turn stimulate magnocellular neurones in the PVN and the SON to release OT from the neurohypophysis (Cunningham \& Sawchenko 1991, Oliet \& Bourque 1993, Somponpun et al. 2004). Therefore, our results from this study indicate that refeeding after fasting increases plasma osmolality, which in turn activates OT neurones in the PVN and the SON to release OT to the plasma.

$\mathrm{E}_{2}$-primed OVX animals that were refed after $48 \mathrm{~h}$ of fasting had a lower co-expression of FOS protein in OT neurones of the PVN and the SON when compared to unprimed OVX animals. Thus, in our experimental model, estrogen inhibited the activation of oxytocinergic neurones induced by refeeding.

The influence of estrogen on the balance of body fluids has been frequently investigated, although its effects are not fully understood (Curtis 2009). Therefore, the mechanism used by estrogen to control the secretion of OT is complex and poorly understood. The variation in food and water intake has been demonstrated during the estrous cycle, due to increased estrogen secretion. Food and water intake decrease during pro-estrous and estrous. Also, urinary output and urinary sodium excretion are decreased in estrous compared to diestrus (Forsling \& Peysner 1988). It is known that physiological concentrations of estrogen stimulate the release of OT by the dendrites of magnocellular neurones in the SON (Wang et al. 1995), and studies in our laboratory have shown that the secretion of OT varies during the estrous cycle, increasing during pro-estrous and the morning of estrous (Caligioni \& Franci 2002). In addition, several studies have shown that estrogen may regulate many aspects of the function of OT neurones, including the expression of OT mRNA (Shughrue et al. 2002), peptide synthesis (Levin \& Sawchenko 1993), electrical activity (Negoro et al. 1973) and the release of OT (Skowsky et al. 1979). In turn, OT inhibits salt appetite (Stricker \& Verbalis 1987), reduces food consumption (Arletti et al. 1989), induces the expression of the FOS protein in regions involved in the control of food intake (Olson et al. 1993) and causes natriuresis directly mediated by kidney OT receptors (Verbalis et al. 1991) or indirectly through stimulation of the atrial natriuretic peptide release from heart (McCann et al. 1994, Gutkowska et al. 1997). 

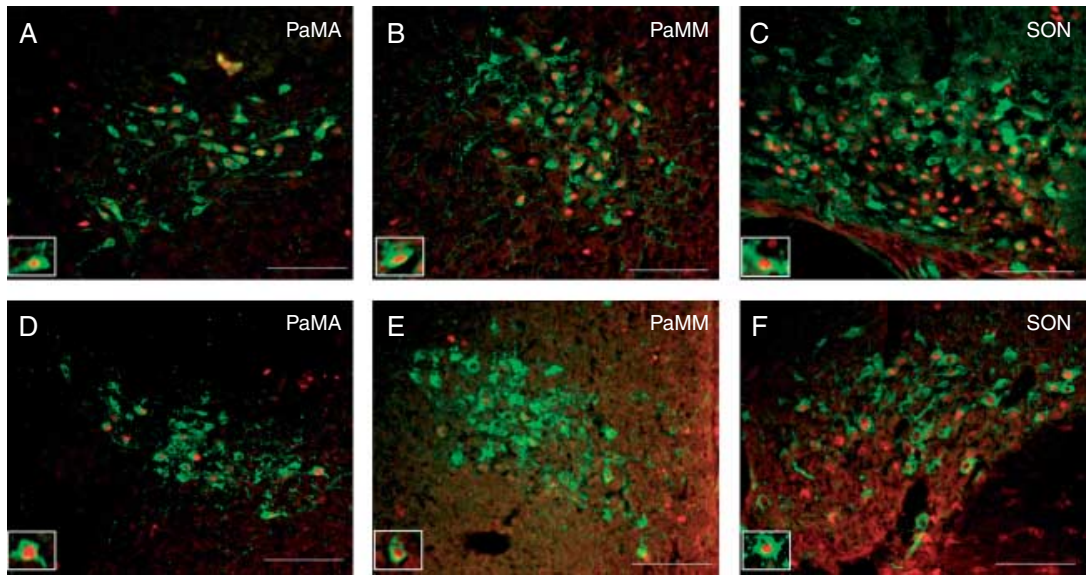

Figure 5 Photomicrographs $(20 \times)$ showing colocalization of OT-ir (green) and FOS-ir (red) in coronal sections $(14 \mu \mathrm{m})$ from the PaMM and PaML portions of the PVN and the supraoptic nucleus (SON) of ovariectomized (OVX) rats treated with vehicle $(\mathrm{A}-\mathrm{C})$ or estrogen $(\mathrm{D}-\mathrm{F})$ and refed with standard food after fasting for $48 \mathrm{~h}$. In each panel (A-F), the magnification of a neurone OT-FOS-ir is shown in square on the left bottom corn. Scale bar: $100 \mu \mathrm{m}$.

Our study was the first to analyze the interaction of the effect of osmotic stimulus induced by refeeding and estrogen influence on OT system activity. We have shown that estrogen hindered or reduced the activation of OT system normally induced by the increase of osmolality, in the refeeding condition. Taken together, our results and literature reports indicate that estrogen and OT could induce similar responses in some situations or some estrogen actions could be mediated by OT. How does estrogen modify the response of the OT system to the hyperosmolality induced by refeeding after fasting? Is it a direct action on OT neurones or an indirect action through circumventricular organs or both?

The idea that estrogen may directly regulate OT neurones is highly controversial. Previous studies suggest that estrogen directly regulates the gene expression of OT in the PVN and the SON through ER- $\beta$ (Shughrue et al. 1996, Laflamme et al. 1998, Somponpun \& Sladek 2003, Hrabovszky et al. 2004). Thus, estrogen increases the level of OT mRNA in neurones of the PVN and SON (Chung et al. 1991, Amico et al. 1995) and increases plasma OT levels (Amico et al. 1981, Wang et al. 1995, Caligioni \& Franci 2002). The expression of ER- $\beta$ in OT neurones is well established in the literature for the PVN, but has not been observed in the SON (Shughrue et al. 1996, Simonian \& Herbison 1997, Alves et al. 1998, Hrabovszky et al. 1998, Laflamme et al. 1998, Somponpun \& Sladek 2003, Suzuki \& Handa 2005). There are conflicting data regarding the SON because some researchers have demonstrated the expression of ER- $\beta$ mRNA and protein in the SON (Laflamme et al. 1998, Hrabovszky et al. 2004).

It has been reported that treatment with estrogen in OVX rats promotes a decrease in ER- $\beta$ expression in the PVN (Suzuki \& Handa 2004). Moreover, variation in the expression of ER- $\beta$ was not found to be dependent on the concentration of a circulating gonadal steroid (Greco et al. 2001). Somponpun \& Sladek (2003) found that the expression of ER- $\beta$ is negatively correlated with changes in plasma osmolality in males. This regulation only occurred in magnocellular neurones of the PVN and the SON that were activated in response to an osmotic stimulus. ER- $\beta$ protein is located in the nucleus of magnocellular and parvocellular neurones and the attenuation of ER- $\beta$ expression occurs in both AVP and OT neurones hyperosmotically stimulated. This alteration of ER- $\beta$ expression could suppress the inhibitory effect to facilitate a greater increase in the secretion of AVP and OT.

Adult rats release AVP and OT in response to osmotic stimuli even in the presence of circulating estrogen (Caligioni \& Franci 2002, Vilhena-Franco et al. 2011). The downregulation of ER- $\beta$ during hyperosmolality may remove this inhibitory influence, allowing the release of AVP and OT in situations that require maximum secretion. Changes in receptor expression may alter the responsiveness of target cells and determine the physiological conditions in which gonadal steroids act to regulate cellular function (Somponpun \& Sladek 2003). On the other hand, our data show that estrogen hindered or reduced the activation of OT system normally induced by the increase of osmolality in the refed condition after fasting. This condition could characterize another mechanism that allows the action of estrogen to take advantage of the osmotic stimulation. Maybe estrogen could be changing the sensitivity of the osmoreceptor mechanisms related to the control of activity of OT neurones.

In our study, approximately half of the neurones that expressed FOS protein in the PVN and the SON were OT-ir. Thus, other non-oxytocinergic neurones in the PVN and the SON are also activated by refeeding. These neurones may, at least in part, be AVP neurones that also participate in the control of hydroelectrolytic balance (Skott 2004, Timofeeva et al. 2005, Curtis 2009). However, as the expression of FOS was lower in OVX estrogen-treated animals that were refed 
after fasting, and some of the vasopressinergic neurones may be involved, we cannot rule out a role for estrogen in inhibiting the release of AVP through ER- $\beta$ (Skowsky et al. 1979, Skott 2004). The presence of gonadal steroids certainly does not eliminate the control of AVP release, but it could modulate the response.

Additionally, we cannot rule out a possible indirect regulation of estrogen on OT and AVP neurones via ER- $\alpha$, which is expressed in neurones located in the organum vasculosum of lamina terminalis and the medial preoptic area, where projections to the SON originate (Voisin et al. 1997, Sladek \& Somponpun 2007, Grassi et al. 2010). However, these brain areas were not a focus of this work.

Other point to consider should be a possible activation of oxytocinergic neurons by gastric distension induced by refeeding. Gastric distension may stimulate satiety mechanisms and cause a slight increase in OT secretion in rats (McCann et al. 1988). This distension may activate the area postrema (AP) and the nucleus of the solitary tract (NTS) in rats through vagal excitatory signals. These areas send projections to specific structures of the brain involved in control of eating behavior, such as the dorsomedial hypothalamus, PVN and central amygdala (Ricardo \& Koh 1978, Rinaman et al. 1998). It has been shown that refeeding increases the expression of FOS in the PVN, SON, NTS and AP (Timofeeva et al. 2002). NTS neurons activated by gastric distension project primarily to the parvocellular portion in the PVN, while the magnocellular division is activated by stimulation from oropharyngeal region, osmoreceptors or circumventricular organs such as the SFO (Starbuck \& Fitts 2002, Timofeeva et al. 2005). Our work has analyzed the magnocellular portion in the PVN, so our results are probably not due to gastric distension.

When the previously cited literature and the data from this study are taken together, we can make the following conclusions: first, in OVX animals, treatment with estrogen reduced the activity of $\mathrm{OT}$ neurones due to the increase in osmolality induced by refeeding after fasting. This reduced activity occurred despite a probable downregulation of ER- $\beta$ caused by the osmotic stimulus induced by refeeding after fasting. Also, in unprimed OVX animals, the absence of estrogen allowed for the highest activity of OT neurones due to the increase in osmolality induced by refeeding after fasting.

\section{Conclusion}

The present study aimed to investigate the effect of estrogen on OT in response to increased osmolality, due to refeeding. We found that OVX rats treated with estrogen had a lower activation of OT neurones induced by refeeding when compared to OVX rats treated with a vehicle control. Thus, our data show that estrogen exerts an inhibitory effect on the activity of oxytocinergic neurones, which is increased by refeeding-induced osmolality after fasting.

\section{Declaration of interest}

The authors declare that there is no conflict of interest that could be perceived as prejudicing the impartiality of the research reported.

\section{Funding}

This work was supported by São Paulo State Research Foundation (FAPESP), the CAPES Foundation and the Brazilian National Council of Research (CNPq).

\section{Acknowledgements}

The authors are grateful to Rogério Rosário Azevedo for technical support.

\section{References}

Alves SE, Lopez V, McEwen BS \& Weiland NG 1998 Differential colocalization of estrogen receptor beta (ERbeta) with oxytocin and vasopressin in the paraventricular and supraoptic nuclei of the female rat brain: an immunocytochemical study. PNAS 95 3281-3286. (doi:10.1073/ pnas.95.6.3281)

Amico JA, Seif SM \& Robinson AG 1981 Elevation of oxytocin and the oxytocin-associated neurophysin in the plasma of normal women during midcycle. Journal of Clinical Endocrinology and Metabolism 53 1229-1232. (doi:10.1210/jcem-53-6-1229)

Amico JA, Crowley RS, Insel TR, Thomas A \& O'Keefe JA 1995 Effect of gonadal steroids upon hypothalamic oxytocin expression. Advances in Experimental Medicine and Biology 395 23-25.

Argiolas A 1992 Oxytocin stimulation of penile erection. Pharmacology, site, and mechanism of action. Annals of the New York Academy of Sciences 652 194-203. (doi:10.1111/j.1749-6632.1992.tb34355.x)

Arletti R, Benelli A \& Bertolini A 1989 Influence of oxytocin on feeding behavior in the rat. Peptides 10 89-93. (doi:10.1016/01969781(89)90082-X)

Balment RJ, Brimble MJ \& Forsling ML 1980 Release of oxytocin induced by salt loading and its influence on renal excretion in the male rat. Journal of Physiology 308 439-449.

Björkstrand E \& Uvnãs-Moberg K 1996 Central oxytocin increases food intake and daily weight gain in rats. Physiology \& Behavior 59 947-952. (doi:10.1016/0031-9384(95)02179-5)

Bloom SR, Edwards AV, Hardy RN, Malinowska K \& Silver M 1975 Cardiovascular and endocrine responses to feeding in the young calf. Journal of Physiology 253 135-155.

Bourque CW 1989 Ionic basis for the intrinsic activation of rat supraoptic neurons by hyperosmotic stimuli. Journal of Physiology 417 263-277.

Burlet AJ, Jhanwar-Uniyal M, Chapleur-Chateau M, Burlet CR \& Leibowitz SF 1992 Effect of food deprivation and refeeding on the concentration of vasopressin and oxytocin in discrete hypothalamic sites. Pharmacology, Biochemistry and Behavior 43 897-905. (doi:10.1016/0091-3057(92) 90423-D)

Caldwell JD 1992 Central oxytocin and female sexual behavior. Annals of the New York Academy of Sciences 652 166-179. (doi:10.1111/j.1749-6632. 1992.tb34353.x)

Caldwell JD, Jirikowski GF, Greer ER, Stumpf WE \& Pedersen CA 1988 Ovarian steroids and sexual interaction alter oxytocinergic content and distribution in the basal forebrain. Brain Research 446 236-244. (doi:10. 1016/0006-8993(88)90882-7)

Caligioni CS \& Franci CR 2002 Oxytocin secretion induced by osmotic stimulation in rats during the estrous cycle and after ovariectomy and hormone replacement therapy. Life Sciences 71 2821-2831. (doi:10.1016/ S0024-3205(02)02139-2) 
Chung SK, McCabe JT \& Pfaff DW 1991 Estrogen influences on oxytocin mRNA expression in preoptic and anterior hypothalamic regions studied by in situ hybridization. Journal of Comparative Neurology 307 281-295. (doi:10.1002/cne.903070209)

Crowley WR, O’Donohue TL, George JM \& Jacobowitz DM 1978 Changes in pituitary oxytocin and vasopressin during the estrous cycle and after ovarian hormones: evidence for mediation by norepinephrine. Life Sciences 23 2579-2586. (doi:10.1016/0024-3205(78)90373-9)

Crowley RS, Insel TR, O'Keefe JA \& Amico JA 1993 Cytoplasmatic oxytocin and vasopressin gene transcripts decline postpartum in the hypothalamus of the lactating rat. Endocrinology 133 2704-2710. (doi:10.1210/en.133.6.2704)

Cunningham ETJR \& Sawchenko PE 1991 Reflex control of magnocellular vasopressin and oxytocin secretion. Trends in Neurosciences 14 406-410. (doi:10.1016/0166-2236(91)90032-P)

Curtis KS 2009 Estrogen and the central control of body fluid balance. Physiology \& Behavior 97 180-192. (doi:10.1016/j.physbeh.2009.02.027)

Fisher HE, Aron A \& Brown LL 2006 Romantic love: a mammalian brain system for mate choice. Philosophical Transactions of Royal Society B 361 2173-2186. (doi:10.1098/rstb.2006.1938)

Fitzsimons JT 1998 Angiotensin, thirst, and sodium appetite. Physiological Reviews 78 583-686.

Forsling M \& Peysner K 1988 Pituitary and plasma vasopressin concentrations and fluid balance throughout the oestrous cycle of the rat. Journal of Endocrinology 117 397-402. (doi:10.1677/joe.0.1170397)

Gill GV, Baylis PH \& Davison SJ 1985 Changes in plasma solutes after food. Journal of the Royal Society of Medicine 78 1009-1013.

Grassi D, Amorim MA, Garcia-Segura LM \& Panzica G 2010 Estrogen receptor alpha is involved in the estrogenic regulation of arginine vasopressin immunoreactivity in the supraoptic and paraventricular nuclei of ovariectomized rats. Neuroscience Letters 474 135-139. (doi:10.1016/j. neulet.2010.03.022)

Greco B, Allegretto EA, Tetel MJ \& Blaustein JD 2001 Coexpression of ER $\beta$ with $\mathrm{ER} \alpha$ and progestin receptor proteins in the female rat forebrain: effects of estradiol treatment. Endocrinology 142 5172-5181. (doi:10.1210/en.142. 12.5172)

Greer ER, Caldwell JD, Johnson MF, Prange AJ \& Pedersen CA 1986 Variations in concentration of oxytocin and vasopressin in the paraventricular nucleus of the hypothalamus during the estrous cycle in rats. Life Sciences 38 2311-2318. (doi:10.1016/0024-3205(86)90638-7)

Gutkowska J, Jankowski M, Lambert C, Mukaddam-Daher S, Zingg HH \& McCann SM 1997 Oxytocin releases atrial natriuretic peptide by combining with oxytocin receptors in the heart. PNAS 94 11704-11709. (doi:10.1073/pnas.94.21.11704)

Hartley DE, Dickson SL \& Forsling ML 2004 Plasma vasopressin concentrations and Fos protein expression in the supraoptic nucleus following osmotic stimulation or hypovolaemia in the ovariectomized rat: effect of oestradiol replacement. Journal of Neuroendocrinology 16 191-197. (doi:10.1111/j.0953-8194.2004.01150.x)

Hiyama TY, Watanabe E, Okado H \& Noda M 2004 The subfornicial organ is the primary locus of sodium-level sensing by Na sodium channels for the control of salt intake behavior. Journal of Neuroscience 24 9276-9281. (doi:10. 1523/JNEUROSCI.2795-04.2004)

Houpt KA, Baldwin BA, Houpt TR \& Hills F 1983 Humoral and cardiovascular responses to feeding in pigs. American Journal of Physiology 244 279-284.

Hrabovszky E, Kallo I, Hajszan T, Shughrue PJ, Merchenthaler I \& Liposits Z 1998 Expression of estrogen receptor-beta messenger ribonucleic acid in oxytocin and vasopressin neurons of the rat supraoptic and paraventricular nuclei. Endocrinology 139 2600-2604. (doi:10.1210/en.139.5.2600)

Hrabovszky E, Kallo I, Steinhauser A, Merchenthaler I, Coen CW, Petersen SL \& Liposits Z 2004 Estrogen receptor-beta in oxytocin and vasopressin neurons of the rat and human hypothalamus: immunocytochemical and in situ hybridization studies. Journal of Comparative Neurology 473 315-333. (doi:10.1002/cne.20127)

Jirikowski GWF, Caldwell JD, Pedersen CA \& Stumpf WE 1988 Estradiol influences oxytocin-immunoreactive brain systems. Neuroscience $\mathbf{2 5}$ 237-248. (doi:10.1016/0306-4522(88)90022-X)
Jones CW \& Pickering BT 1969 Comparison of the effects of water deprivation and sodium chloride inhibition on the hormone content of the neurohypophysis of the rat. Journal of Physiology 203 449-458.

Kendrick KM, Da Costa AP, Broad KD, Ohkura S, Guevara R, Levy F \& Kevernr EB 1997 Neural control of maternal behavior and olfactory recognition of offspring. Brain Research Bulletin 44 383-395. (doi:10.1016/ S0361-9230(97)00218-9)

Laflamme N, Nappi RE, Drolet G, Labrie C \& Rivest S 1998 Expression and neuropeptidergic characterization of estrogen receptors (ERalpha and ERbeta) throughout the rat brain: anatomical evidence of distinct roles of each subtype. Journal of Neurobiology 36 357-378. (doi:10.1002/ (SICI) 1097-4695(19980905)36:3 < 357::AID-NEU5 > 3.0.CO;2-V)

Levin MC \& Sawchenko PE 1993 Neuropeptide co-expression in the magnocellular neurosecretory system of the female rat: evidence for differential modulation by estrogen. Neuroscience 54 1001-1018. (doi:10. 1016/0306-4522(93)90591-3)

McCann MJ, Verbalis JG \& Stricker EM 1988 Capsaicin pretreatment attenuates multiple responses to cholecystokinin in rats. Journal of the Autonomic Nervous System 23 265-272. (doi:10.1016/0165-1838(88) 90101-4)

McCann SM, Gutkowska J, Franci CR, Favaretto AL \& Antunes-Rodrigues J 1994 Hypothalamic control of water and salt intake and excretion. Brazilian Journal of Medical and Biological Research 27 865-884.

McKinley MJ \& Johnson AK 2004 The physiological regulation of thirst and fluid intake. News in Physiological Sciences 19 1-6. (doi:10.1152/nips.01470. 2003)

McKinley MJ, Hards DK \& Oldfield BJ 1994 Identification of neural pathways activated in dehydrated rats by means of Fos-immunohistochemistry and neural tracing. Brain Research 653 305-314. (doi:10.1016/ 0006-8993(94)90405-7)

Miller FD, Ozimek G, Milner RJ \& Bloom FE 1989 Regulation of neuronal oxytocin mRNA by ovarian steroids in the mature and developing hypothalamus. PNAS 86 2468-2472. (doi:10.1073/pnas.86.7.2468)

Morris M \& Alexander N 1989 Baroreceptor influences on oxytocin and vasopressin secretion. Hypertension 13 110-114.

Naimi N, Rivest S, Ricotta I \& Richard D 1997 Neuronal activation of the hypothalamus magnocellular system in response to oropharyngeal stimuli in the rat. Journal of Neuroendocrinology 9 329-340. (doi:10.1046/j.1365-2826. 1997.00573.x)

Negoro H, Visessuwan S \& Holland RC 1973 Unit activity in the paraventricular nucleus of female rats at different stages of the reproductive cycle and after ovariectomy, with or without oestrogen or progesterone treatment. Journal of Endocrinology 59 545-558. (doi:10.1677/joe.0. 0590545)

Oldfield BJ, Badoer E, Hards DK \& McKinley MJ 1994 Fos production in retrogradely labeled neurons of lamina terminallis following intravenous infusion of either hypertonic saline or angiotensin II. Neuroscience $\mathbf{6 0}$ 255-262. (doi:10.1016/0306-4522(94)90219-4)

Oliet SH \& Bourque CW 1993 Mechanosensitive channels transducer osmossensitivity in supraoptic neurons. Nature 364 341-343. (doi:10.1038/ 364341a0)

Olson BR, Freilino M, Hoffman GE, Stricker EM, Sved AF \& Verbalis JG 1993 c-Fos expression in rat brain and brainstem nuclei in response to treatments that alter food intake and gastric motility. Molecular and Cellular Neurosciences 4 93-106. (doi:10.1006/mcne.1993.1011)

Osterlund MK, Gustafsson JA, Keller E \& Hurd YL 2000 Estrogen receptor beta (ERbeta) messenger ribonucleic acid (mRNA) expression within the human forebrain: distinct distribution pattern to ERaplha mRNA. Journal of Clinical Endocrinology and Metabolism 85 3840-3866. (doi:10.1210/ jc.85.10.3840)

Ricardo JA \& Koh ET 1978 Anatomical evidence of direct projections from the nucleus of the solitary tract to the hypothalamus, amygdala and other forebrain structures in the rat. Brain Research 153 1-53. (doi:10.1016/00068993(78)91125-3)

Rinaman L, Baker EA, Hoffman GE, Stricker EM \& Verbalis JG 1998 Medullary c-Fos activation in rats after ingestion of a satiating meal. American Journal of Physiology 275 R262-R268. 
Ruginsk SG, Oliveira FR, Margatho LO, Vivas L, Elias LLK \& AntunesRodrigues J 2007 Glucocorticoid modulation of neuronal activity and hormone secretion induced by blood volume expansion. Experimental Neurology 206 192-200. (doi:10.1016/j.expneurol.2007.04.012)

Russell JA \& Leng G 1998 Sex, parturition and motherhood without oxytocin? Journal of Endocrinology 157 343-359. (doi:10.1677/joe.0. 1570343)

Salonia A, Nappi RE, Pontillo M, Daverio R, Smeraldi A, Brigant A, Fabbri F, Zanni G, Rigatti P \& Montorsi F 2005 Menstrual cycle-related changes in plasma oxytocinare relevant to normal sexual function in healthy women. Hormones and Behavior 47 164-169. (doi:10.1016/j.yhbeh.2004. 10.002)

Sarkar DK \& Gibbs DM 1984 Cyclic variation of oxytocin in the blood of pituitaryportal vessels of rats. Neuroendocrinology 39 481-483. (doi:10.1159/ 000124024)

Selvage D \& Johnston CA 2001 Central stimulatory influence of oxytocin on preovulatory gonadotropin-releasing hormone requires more than the median eminence. Neuroendocrinology 74 129-134. (doi:10.1159/ 000054678)

Shughrue PJ \& Merchenthaler I 2001 Distribution of estrogen receptor $\beta$ immunoreactivity in the rat central nervous system. Journal of Comparative Neurology 436 64-81. (doi:10.1002/cne.1054)

Shughrue PJ, Komm B \& Merchenthaler I 1996 The distribution of estrogen receptor-beta mRNA in the rat hypothalamus. Steroids 61 678-681. (doi:10.1016/S0039-128X(96)00222-X)

Shughrue PJ, Dellovade TL \& Merchenthaler I 2002 Estrogen modulates oxytocin gene expression in regions of the rat supraoptic and paraventricular nuclei that contain estrogen receptor- $\beta$. Progress in Brain Research 139 15-29.

Simonian SX \& Herbison AE 1997 Differential expression of estrogen receptor alpha and beta immunoreactivity by oxytocin neurons of rat paraventricular nucleus. Journal of Neuroendocrinology 9 803-806. (doi:10. 1046/j.1365-2826.1997.00659.x)

Skott O 2004 Estrogen receptors and central osmotic regulation. American Journal of Physiology. Regulatory, Integrative and Comparative Physiology 286 465-473. (doi:10.1152/ajpregu.00679.2003)

Skowsky WR, Swan L \& Smith P 1979 Effects of sex steroid hormones on arginine vasopressin in intact and castrated male and female rats. Endocrinology 104 105-108. (doi:10.1210/endo-104-1-105)

Sladek CD \& Somponpun SJ 2007 Estrogen receptors: their roles in regulation of vasopressin release for maintenance of fluid and electrolyte homeostasis. Frontiers in Neuroendocrinology 29 114-127. (doi:10.1016/j.yfrne.2007. 08.005)

Somponpun JS 2007 Neuroendocrine regulation of fluid and electrolyte balance by ovarian steroids: contributions from central oestrogen receptors. Journal of Neuroendocrinology 19 809-818. (doi:10.1111/j.1365-2826.2007. 01587.x)

Somponpun S \& Sladek C 2003 Osmotic regulation of estrogen receptor- $\beta$ in rat vasopressin and oxytocin neurons. Journal of Neuroscience 23 4261-4269.

Somponpun SJ, Johnson AK, Beltz T \& Sladek CD 2004 Osmotic regulation of estrogen receptor- $\beta$ expressiona in magnocellular vasopressin neurons requires lamina terminalis. American Journal of Physiology. Regulatory, Integrative and Comparative Physiology 286 465-473. (doi:10.1152/ajpregu. 00478.2003)
Starbuck EM \& Fitts DA 2002 Subfornical organ disconnection and FOS-like immunoreactivity in hypothalamic nuclei after intragastric hypertonic saline. Brain Research 951 202-208. (doi:10.1016/S0006-8993(02)03162-1)

Stricker EM \& Verbalis JG 1987 Central inhibitory control of sodium appetite in rats: correlation with pituitary oxytocin secretion. Behavioral Neuroscience 101 560-567. (doi:10.1037/0735-7044.101.4.560)

Suzuki S \& Handa RJ 2004 Regulation of estrogen receptor-beta expression in the female rat hypothalamus: differential effects of dexamethasone and estradiol. Endocrinology 145 3658-3670. (doi:10.1210/en.2003-1688)

Suzuki S \& Handa RJ 2005 Estrogen receptor-beta, but not estrogen receptoralpha, is expressed in prolactin neurons of the female rat paraventricular and supraoptic nuclei: comparison with other neuropeptides. Journal of Comparative Neurology 484 28-42. (doi:10.1002/cne.20457)

Swanson LW 1992 Structure of the Rat Brain. Brain Maps. pp 240 Elsevier, Amsterdam.

Timofeeva E, Picard F, Duclos M, Deshaies Y \& Richard D 2002 Neuronal activation and corticotrophin-releasing hormone expression in the brain of obese $(\mathrm{fa} / \mathrm{fa})$ and lean $(\mathrm{fa} /$ ?) Zucker rats in response to refeeding European Journal of Neuroscience 15 1013-1029. (doi:10.1046/j.1460-9568.2002. 01942.x)

Timofeeva E, Baraboi ED \& Richard D 2005 Contribution of the vagus nerve and lamina terminalis to brain activation induced by refeeding. European Journal of Neuroscience 22 1489-1501. (doi:10.1111/j.1460-9568.2005. 04330.x)

Van Tol HH, Bolwerk EL, Lui B \& Burbach JP 1988 Oxytocin and vasopressin gene expression in the hypothalamo-neurohypophyseal system of the rat during the estrous cycle, pregnancy, and lactation. Endocrinology 122 945-951. (doi:10.1210/endo-122-3-945)

Verbalis JG, Magione MP \& Stricker EM 1991 Oxytocin produces natriuresis in rats at physiological plasma concentrations. Endocrinology 128 1317-1322. (doi:10.1210/endo-128-3-1317)

Vilhena-Franco T, Mecawi AS, Elias LL \& Antunes-Rodrigues J 2011 Oestradiol potentiates hormone secretion and neuronal activation in response to hypertonic extracellular volume expansion in ovariectomised rats. Journal of Neuroendocrinology 23 481-489. (doi:10.1111/j.1365-2826. 2011.02133.x)

Voisin DL, Simonian SX \& Herbison AE 1997 Identification of estrogen receptor-containing neurons projecting to the rat supraoptic nucleus. Neuroscience 78 215-228. (doi:10.1016/S0306-4522(96)00551-9)

Wang H, Ward AR \& Morris JF 1995 Oestradiol acutely stimulates exocytosis of oxytocin and vasopressin from dendrites and somata of hypothalamic magnocellular neurons. Neuroscience 68 1179-1188. (doi:10.1016/03064522(95)00186-M)

Windle RJ \& Forsling ML 1993 Variations in oxytocin secretion during the 4-day oestrous cycle of the rat. Journal of Endocrinology 136 305-311. (doi:10.1677/joe.0.1360305)

\section{Received in final form 25 October 2011 Accepted 14 November 2011 Made available online as an Accepted Preprint 14 November 2011}

